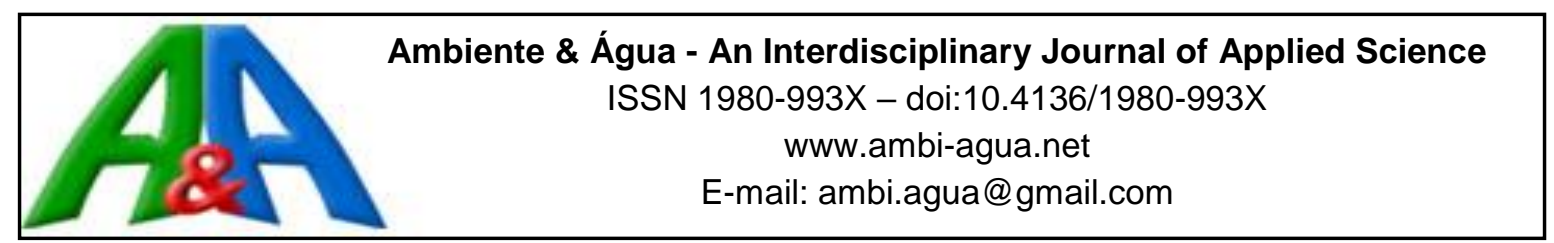

\title{
Natural vector multi-agents geo-inspired in environmental management
}

\author{
doi:10.4136/ambi-agua.1912
}

Received: 05 Apr. 2016; Accepted: 29 Oct. 2016

\author{
Edwin Eduardo Millán $\operatorname{Rojas}^{*}$; José Nelson Pérez Castillo ${ }^{2}$ \\ ${ }^{1}$ Universidad de la Amazonia (UDLA), Florencia, Colombia \\ ${ }^{2}$ Universidad Distrital Francisco José de Caldas, Bogotá, Colombia \\ "Corresponding author: e-mail: e.millan@udla.edu.co, \\ jnperezc@correo.udistrital.edu.co
}

\begin{abstract}
Environmental management requires new models to minimize or control the effects of environmental problems on the population. The complexity of environmental problems requires conducting studies to develop models to adjust the environment's dynamics. The proposed geo-inspired model of natural vector multi-agents (Multi-AVNG) allows for the computational observation of the dynamism of the environmental entity studied. This model is based on the theory of vector agents, changing its structure to include the environmental dynamic aspect using only two behaviors, the natural and the induced, through the vector model in geographic information systems and a function which will control the progression of the environmental entity according to the model's defined parameters.
\end{abstract}

Keywords: environmental behavior, multi-Agent model, simulation.

\section{Agentes naturais multi vetores geo-inspirados na gestão ambiental}

\section{RESUMO}

A gestão ambiental requer novos modelos para minimizar ou controlar os efeitos sobre a população causados por problemas ambientais. A complexidade dos problemas ambientais requer a realização de estudos para o desenvolvimento de modelos para ajustar a dinâmica do ambiente. O modelo de geo-inspiração proposto de vetor multi-agentes natural (Multi-AVNG) permite assistir computacionalmente o dinamismo do órgão ambiental estudado. Este modelo é baseado na teoria de agentes vetores, alterando a sua estrutura para incluir o aspecto ambiental dinâmico usando apenas dois comportamentos, o natural e o induzido, por meio do modelo de vetor em sistemas de informação geográfica e uma função que controla a progressão da entidade ambiental de acordo com os parâmetros definidos para o modelo.

Palavras-chave: gestão ambiental, modelo de multi-agente, simulação.

\section{INTRODUCTION}

Environmental problems are complex and dynamic, and they affect the population in general. Climate change, water resources, the use of land, flora and fauna, among others, are 
aspects that require further input from the computer science field in order to model dynamic structures in natural behaviors of the environment and to include functions or control variables for the decision- making process (Cuesta and Becerra, 2012).

Nowadays there are many computational structures (cellular automated, neural networks, genetic algorithms, Neuro-genetics, fuzzy logic, Agents, Multi-agent Systems, etc.) (Batty, 2000; Jayawardena et al., 2014; Vitabile et al., 2009; Chen et al., 2008, Santamaría et al., 2015). These studies contribute to solving the problems of information management and decision-making.

We present a computational structure based on bio-inspired computing in the field of natural agents and the vector model of geographic information systems for decision-making in environmental management. We propose to model the environmental problem from two behaviors:

1) natural behavior, which owns the entity in the normal state and is influenced by a random variable; and

2) induced behavior, which is generated by altering the natural behavior of the entity by environment's variables or functions.

A computational framework was formulated that integrates the concept of agent with the vector model and the control of variables in environmental management, with the purpose of presenting a dynamic model which can visualize, in a geographic information system, the natural and the induced behaviors by nature or by man according to the case study.

A generic model is built based on the Euclidean geometry of the vector model (point, lines, polygons) including the dynamic behavior of a natural agent. This model was developed in JADE and Geotools, which are widely proven tools.

General aspects were established for the implementation of the AVNG in environmental management, for which we present the model structure and variables or behaviors to remember at the time of analysis and construction. Additionally, we present an application of the model in an environmental problem related to the flooded urban areas.

In the results, the data generated by the Multi- AVNG model versus the flooded urban areas are presented. These results were compared with an evaluation method used by (Horritt and Bates, 2002) which was used to calculate in percentage the areas generated by the model against historical data obtained from a map of the flooded area.

We also investigated models that support environmental management based on computer science inspired by environmental phenomena. There are also comments about related works in the area of vector agents. This model will help to dynamically visualize the elements or entities involved in the several environmental problems. For this purpose, the model is based on two behaviors which can be fed back or defined in multiple ways.

\section{Model natural vector agents inspired in environmental management or geo-inspired (AVNG)}

In this section, theoretical aspects related to the origin of the AVNG are presented, giving a brief explanation of the vector agents (Hammam et al., 2007) and their difference with the natural vector agents as proposed in this paper, as well as the environmental management inspired by elements that complete the structure of AVNG. The description of the geometrical aspects of the vector model is included and as well as an explanation of how all these aspects are integrated into the proposal of the geo-inspired natural vector agents.

\subsection{Proposal of a geo-inspired natural vector agent (AVNG)}

The AVNG is founded on the integration of the environmental aspects modeled in two 
behaviors and the use of the theory of vector agents (Hammam et al., 2007) based on Euclidian geometry. A geo-inspired natural vector agent represents a geographic or environmental entity in which two behaviors can be modeled: the natural and the induced. The first behavior corresponds to the natural state of the entity, its role in nature, which can be modified by physical variables without significant changes. In this study, the natural variables were modeled randomly. The second behavior is the one presented by the entity when it overflows the natural function. This occurs when it is affected by one or more generated physical variables. At that time, the natural behavior is transformed into induced behavior.

After these behaviors, the geographical function was established, which helps to integrate the visual component systems of geographic information from the vector model that represents entities through primitives (points, lines or polygons). Each geographic entity has an initial vector that represents it. Natural behavior is associated with the initial vector and from this the necessary adjustments are made toward the induced behavior, to show its spatial variation. The last component is the function of environmental management that provides the control for the behavior variable or induced function of the agent.

\subsection{Variables and functions to consider}

The elements to consider in the analysis of an environmental problem at the time of modeling the Multi-AVNG are set forth below. We need to identify these elements to properly structure the operation of agents. The problem to address is the visualization of the flooded areas after a strong precipitation.

Natural behavior. The natural form, from the mathematical and computational points of view, can be defined as a function, which represents the natural behavior of the entity. For this study, we will call it $(q)$, where the value of this function is represented according to what is to be studied, e.g. the flow of a river.

Induced behavior. For practical purposes, this agent's function was defined as the behavior that the agent assumes once it has been influenced by the variable or the function of the environment; this function is called $I(q)$, e.g. the flow of a river's flooding.

The environment's function or variable. This function or variable of the environment is responsible for altering the natural behavior and setting the induced behavior in the environmental entity studied. In the case that it is variable, it can be one or several variables involved in the change of behavior of the environmental entity. As an example of this, based on the initial environmental problem, we can speak of the rainfall.

Memory. This is the variable that stores the induced behavior in a time (t) to be transmitted to the same AVNG or another in its context.

Geographic feature. The geographical feature is what allows vectoring the induced behavior from the difference between its two behaviors in a range of time-definite (Equations 1, 2, 3 and 4).

$$
\mathrm{G}\left(\text { dist }_{\mathrm{i}}\right)=\mathrm{E}\left(\text { dist }_{\mathrm{i}}\right) * \mathrm{C}
$$

With $(\mathrm{M})$ memory $=0$, the equation is shown below:

$\mathrm{E}\left(\right.$ dist $\left._{\mathrm{i}}\right)=\sqrt[r]{(\mathrm{I}(\mathrm{q})-\mathrm{N}(\mathrm{q})) * \mathrm{~F}(\mathrm{t})}$

With (M) memory $>0$ the equation takes form:

$\mathrm{E}\left(\right.$ dist $\left._{\mathrm{i}}\right)=\sqrt[\mathrm{r}]{\mathrm{I}(\mathrm{q}) * \mathrm{~F}(\mathrm{t})}$ 


$$
\begin{array}{lll}
\text { lat }_{0} & \left(\operatorname{long}_{0}+\mathrm{G}\left(\text { dist }_{0}\right)\right) & \mathrm{h}_{0} \\
\text { lat }_{1} & \left(\operatorname{long}_{1}+\mathrm{G}\left(\text { dist }_{1}\right)\right) & \mathrm{h}_{1} \\
\text { lat }_{\mathrm{n}} & \left(\operatorname{long}_{\mathrm{n}}+\mathrm{G}\left(\text { dist }_{\mathrm{n}}\right)\right) & \mathrm{h}_{\mathrm{n}}
\end{array}
$$

where:

$F(t)=$ Function or variable of time;

$N(q)=$ Natural behavior;

$I(q)=$ Induced behavior;

$\operatorname{lat}_{n} ; \operatorname{long}_{n}=$ values for latitude and longitude in the $\mathrm{n}$ section;

$h_{n}$ value of altitude at the point $\mathrm{n}$;

$\mathrm{C}$ is a constant derived from the unit of measure of the shapefile of reference given in meters; and

$$
G\left(\text { dist }_{i}\right)=\text { to the geographical function that calculates the distance the vector moves. }
$$

We work with the vector model and define the primitive and the spatial reference system to analyze each vector agent; $r$ is the integer value that assumes the root; this will depend on the induced behavior units, e.g. for $\mathrm{r}=1 ; \mathrm{m}^{2}, \mathrm{r}=2$ y para $\mathrm{m}^{3} \mathrm{r}=3$.

Environmental management function. The environmental management function is the one which controls the induced behavior of the entity. This function seeks to have degrees of tolerance between the natural behavior and the induced behavior, for issuing an alert when it is above the limits.

\section{RESULTS}

As a result of the implementation of the Multi-AVNG system, the study area and the source of the data for the system was determined, the data set was constructed for processing, the vectorization environmental entity was studied, and a comparison was made between the area generated by the AVNG model and the historical area demarcated by the event that occurred on April 28, 2000.

\subsection{Multi-AVNG system to determine a flooded urban area}

For the use of the Multi AVNG system, a case study is presented to address the problem of the flooded areas in an urban center. For that purpose, the study area is described and the functions and behaviors to model for the use of the proposed system are determined.

\subsubsection{Case study}

La Perdiz stream, located in the Amazon region, in the southeast of Colombia, South America between $00^{\circ} 42^{\prime} 17$ " of South latitude and $02^{\circ} 04^{\prime} 13$ "North latitude and $74^{\circ} 18^{\prime} 39^{\prime \prime}$ and $79^{\circ} 19^{\prime} 35$ " longitude West, representing $7.8 \%$ of the territory Colombian, lies in the municipality of Florencia, capital of the Department of Caquetá. This river represents a clear example of the damage that small streams can cause in urban centers. Flooding in the stipulated conditions has been little studied in this part of the world, given the conditions of the Amazonian foothills, where the mountainous landscape converges with plains; this variety of landscape makes it the ideal place to test the AVNG model for the definition of probable flooded areas. 


\subsubsection{Data source to apply to the Multi-AVNG system for study}

The development of the geographical work had multiple sources of digital information, enabling the performance of the case study. The main sources were the land ordinance plan (POT); a satellite image of Landsat 7 (La Perdiz River Basin); nine (9) aerial photography flights C-2173 IGAC; and three (3) official plates IGAC, numbered 389-VI-C and 413-II-A Scale C 1: 25000. Based on these data, networks of irregular triangles (TIN) and the base layers of the vectors representing the environmental agency (La Perdiz River) were obtained.

The hydrographic data were obtained from the Institute of Hydrology, Meteorology and Environmental Studies of Colombia (IDEAM, after its abbreviation in Spanish). The data from 1969 to 2014 were obtained from the stations that the IDEAM has in the region. Based on these data, the study of the worst flooding that the municipality has suffered was consolidated and the water flow that generated these floods was established, to test the model in a known context and to validate the data with recorded historical data and flooded areas, which were demarcated with precipitation. On May 24, 2003, ten districts were flooded, injuring approximately 1,500 people.

The most disastrous effects occurred in the road infrastructure and in the networks of the aqueduct, the services of which were suspended for more than ten days in some districts of the city. Two months later, on July 14th of the same year, a new hydro-climate event occurred which injured a reported 1,030 families, for a total of 5,200 affected people.

\subsubsection{Definition of the test dataset}

The test dataset was built with the recorded precipitations at the meteorological station. A consolidated 12-hour time lapse was done to determine the behavior of the basin with certain pre-set values with intervals of an hour, because historically, the sudden floods caused by rain took place between three to six hours; a margin for the consolidation of the results was maintained. In addition, the physical parameters of the basin, as area and velocity of flows in the stipulated sections, were integrated to define the parameters of the Natural function. The Induced function occurs when the precipitation or rainfall is greater than 0 in the one-hour time lapse.

The file can be built as a table in Excel or a flat file for which some libraries of the source code must be modified. Fixed values taken from the historical data of the time of one of the severe floods that have occurred in this territory were used for the simulation. On April 28, 2000, approximately 65, 60 and $150 \mathrm{~mm}$ of rain (IDEAM, 2015) fell for a period of three hours. For future work, the file can be linked with sensors located in the course of the basin and in this way to achieve data in real-time.

\subsubsection{Vectorization of the geographical entity (La Perdiz stream)}

From the geographical information obtained from data sources already stipulated, a set of vectors was defined that will represent the entity to process. This research identified the area and shape of the basin, important factors for the calculation of the induced behavior. The geographic entity for the case study, La Perdiz stream, was divided into 71 tranches, by noting 71 variations of its descent along the path from its origin to where it flows into the Hacha River. The purpose of this division is to have minor variations in the shape of the volume of water that runs along the riverbed. Once the entity is vectored, it is input to the AVNG system.

The flexibility of the vector model in GIS allows one to represent any entity through its primitives. It is necessary to perform a preliminary analysis to determine which of them is the one that represents correctly the appropriate scale for the geographic entity of the study. 


\subsubsection{Definition and processing of the Multi-AVNG system}

When the entries are defined (the dataset and the vector representing the geographic entity for the AVNG) an area demarcated by vectors that were affected by the overflowing water is obtained.

Once the data were entered into the AVNG (Dataset), each of the paths of the entity are analyzed and checked to determine if the entity is in its Natural behavior or changes to its Induced behavior, for which rainfall values supplied by the Dataset are verified. Once comparison is done, the next step is to store the value modified in the stretch in the variable memory. This value sends a message through to the following AVNG, which is monitoring the next section. The value obtained from the sent message becomes an additional entrance to the AVNG that receives it and it accumulates to the flow of the Natural or Induced function given the situation. In this way, all AVNG communicate as a cascade from the birth of the La Perdiz stream to its mouth.

The geographic function is initialized with the values obtained in each section before being sent to the next AVNG. These are functions take the values of the original vector' points and modify them by adding the values generated by the induced function to create vectors to move the original stretch. The area obtained from the execution of the AVNG is displayed in Figure 1, where it is demarcated from vectors that move from the original vector to the left or right according to the induced function, which is affected by the slope, rainfall values and the flow generated by precipitations.

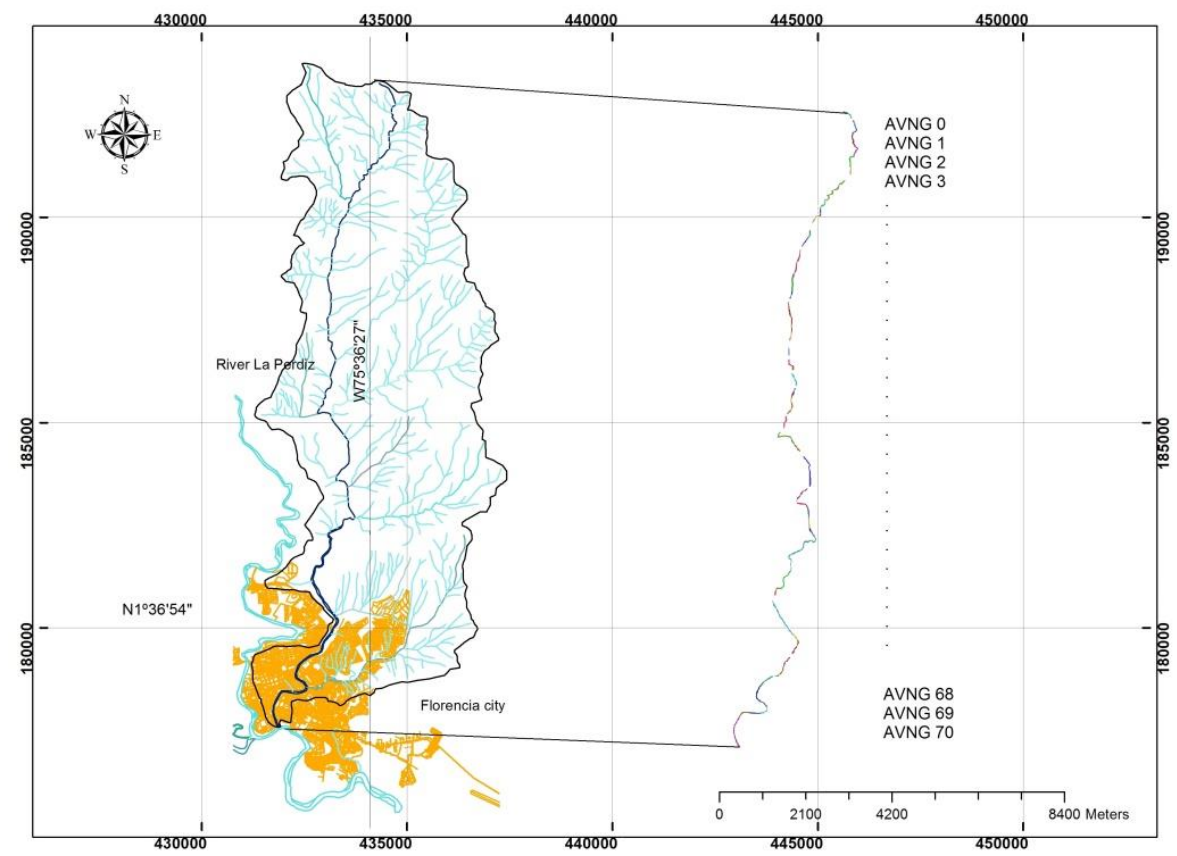

Figure 1. Environmental entity is divided into equal vectors slope and is assigned a AVNG to monitor behaviors.

\subsection{Comparison of the areas between the Multi-AVNG system and the flooded area}

The city of Florence is shown in Figure 2; in the larger scale it is divided by neighborhoods, streets, roads and avenues. The urban area is at the South part of the municipality of Florence and it is crossed by multiple sources of water including the $\mathrm{La}$ Perdiz stream. 


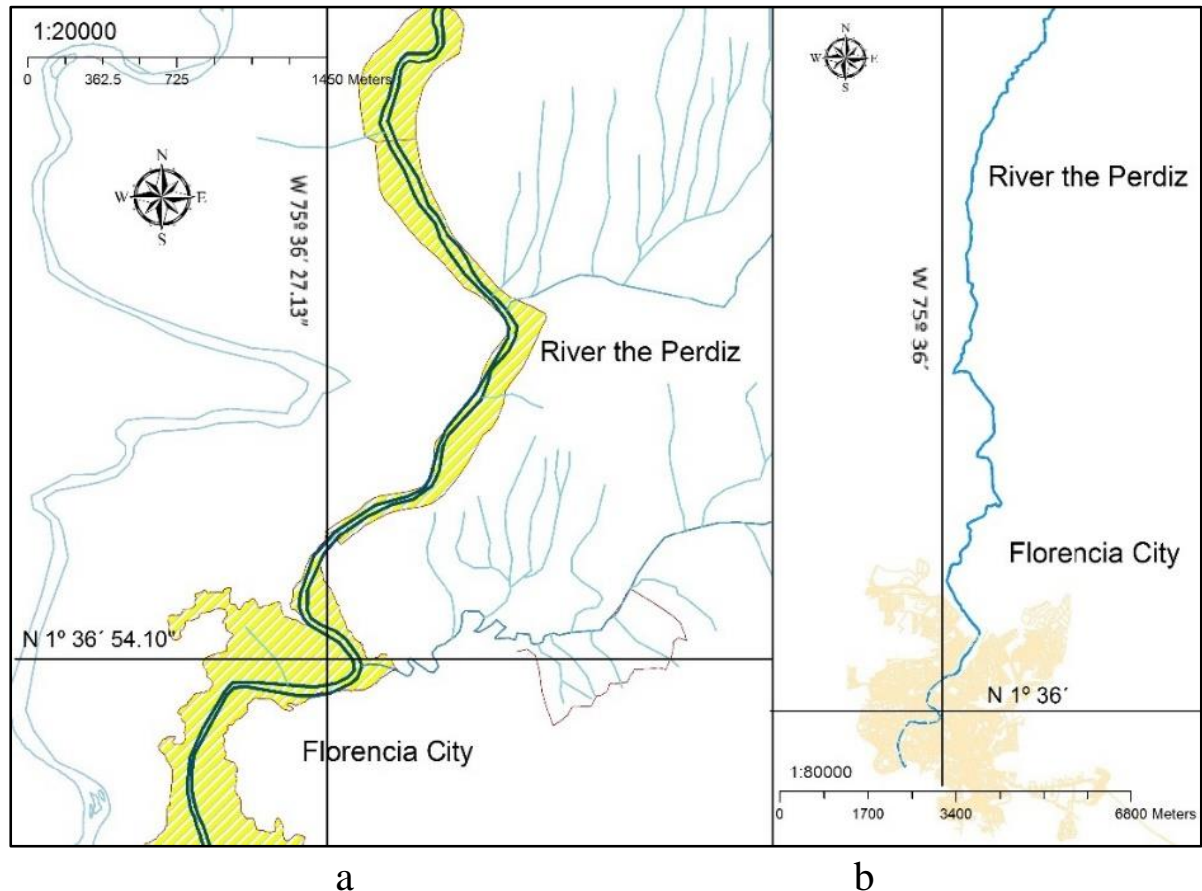

Figure 2. Area flooded historically (yellow) and a channel of the water entity. Figure $2 a$, the entity hydric basin. Figure $2 b$.

A shapefile that defines this area was obtained from the satellite image showing the flooded area and compared with the vectors generated by the Multi-AVNG system that obtained a shapefile with the generated sections; see Figure 3. The comparison of the two results is shown in Figure 4, where there is evidence of differences between the defined area and the obtained by the AVNG.

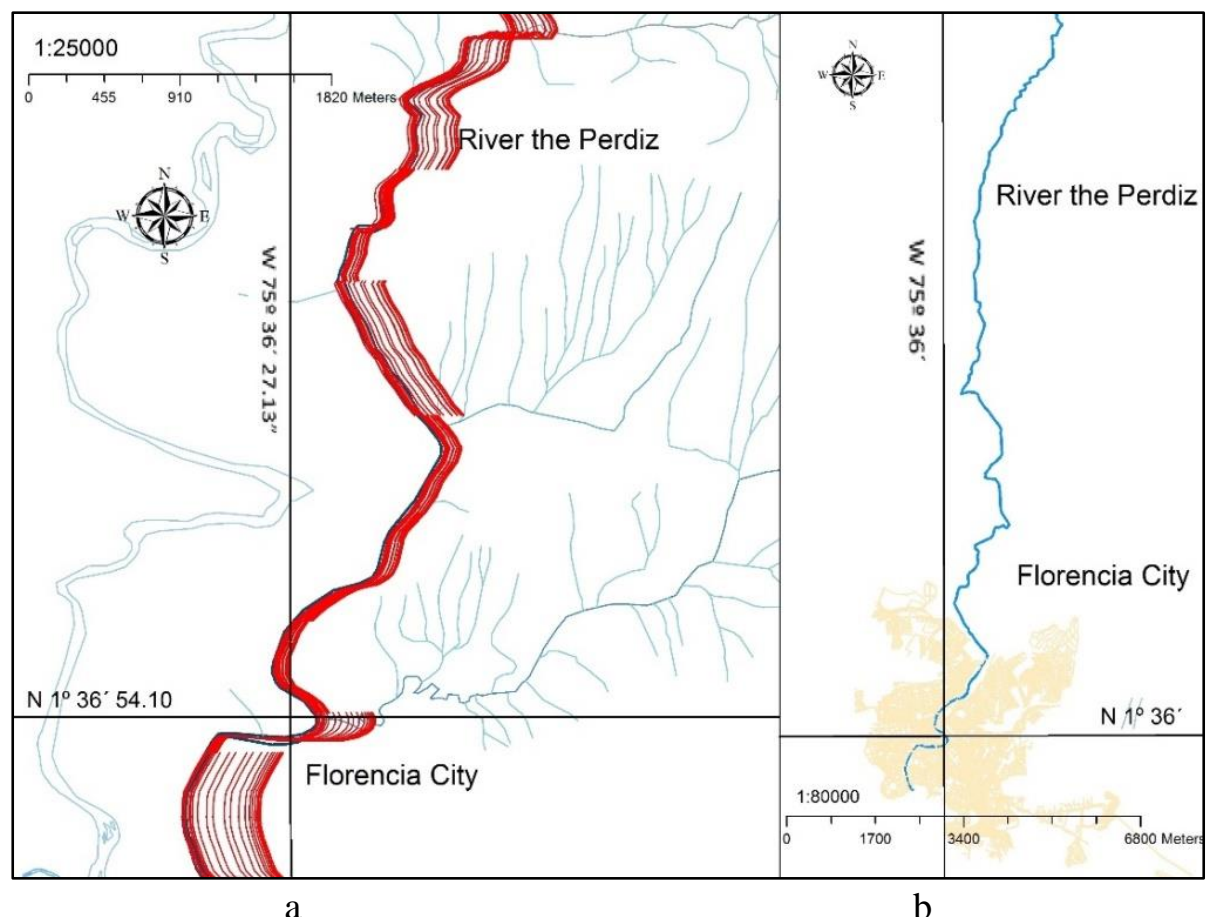

Figure 3. Area marked by the AVNG. Figure 3a, the entity hydric basin. Figure $3 b$. 


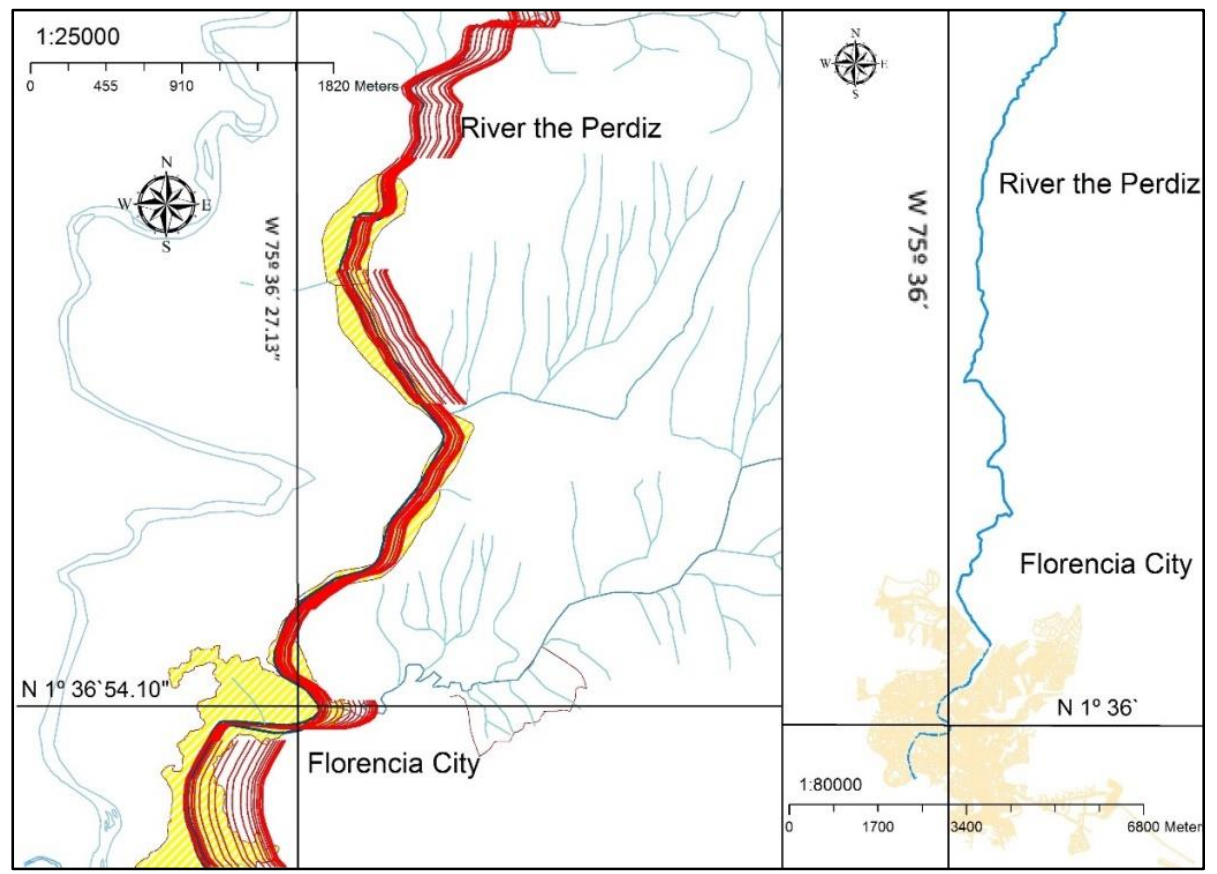

Figure 4. Historically flooded area (yellow) versus the area generated by the AVNG system (red).

Once the areas generated by the Multi-AVNG system were obtained, the next step was to take the farthest vector from the origin vector, to the left and the right sides to get an area over the TIN or raster-generated. From this information, the method used by (Horritt and Bates, 2002) was employed to calculate the percentage of approximation of the flooded area and the area generated by the system, for which Equation 5 was used.

$$
F=\frac{\operatorname{Num}\left(S_{\text {mod }} \cap S_{o b s}\right)}{N u m\left(S_{\text {mod }} \cup S_{o b s}\right)} \times 100
$$

where:

$S_{\text {mod }}$ y $S_{\text {obs }}$ are the sets of domain sub-regions (pixels, items or cells) shown as flooded by the model and the historical data reflected in maps or satellite images; and

$\operatorname{Num}(\bullet)$ denotes the number of members of the joint.

Therefore, it varies between zero, for the model without overlapping between the flooded areas, and 100, for a model in which the forecast data fully coincide with those observed (Horritt and Bates, 2002). The results can be seen in Table 1.

Table 1. Results in percentage of the flooded area generated by the Multi-AVNG model vs. flooded area.

\begin{tabular}{lccc}
\hline \multicolumn{1}{c}{ Data } & $\begin{array}{c}\text { Generated area vs. } \\
\text { Flooded area (\%) }\end{array}$ & Error submitted (\%) & With settings \\
\hline $\begin{array}{l}\text { Event April 28, 2000 } \\
\text { (flooded area) }\end{array}$ & 100.0 & 0.0 & No \\
Multi- GNVA Model & 70.3 & 29.7 & No \\
$\begin{array}{l}\text { No event Multi- } \\
\text { GNVA Model }\end{array}$ & 95.8 & 4.2 & No \\
\hline
\end{tabular}

As it can be seen, when using the method of comparison, 70.29 percent of flooded area was obtained from the Multi-AVNG model, which consolidated a clear area where the 
induced behavior of the agents was an influence. In addition, the model was assessed when there were no rainfall data of catastrophic events. The result was the natural riverbed of the environmental entity; in other words, the system exposed only the natural behavior of the entity, in this case with $95.78 \%$ of area in relation to the normal course of the environmental entity. It is important to be clear that further testing with different events is needed, but in the demonstration, agents change their behaviors and reflect, in the structure of their vector model, an approximation to the behaviors of the environmental entity. Further work can be developed to improve the results.

\section{DISCUSSION AND CONCLUSIONS}

While investigating related works such as geographical vector agents, we found a paper from Hammam et al. (2007) which uses Euclidean geometry to generate an autonomous entity making use of the vector model, based on the concept of cellular automaton (Batty, 2000).

Environmental and geographical features were integrated into the system agents to have a flexible structure in the representation of water environmental entities.

In this paper, the concept of the geo-inspired natural vector agent was addressed from the concept of vector agent inspired by the environmental management. The AVNG formulates the creation of a multi-agent system based on the entity's natural behavior and induced behavior by variables or environmental functions.

A computational implementation of the Multi-AVNG model was developed on the JADE platform with the use of the Geotools library. The selected library allows using point primitive lines or polygons to represent dynamic environmental entities and their problems, from modeling their natural and induced behaviors and also monitoring through the geographical feature and environmental management.

The Multi-AVNG system differs significantly from geographical delivery agents in the following areas: it does not change the initial vector and the results can be displayed in a new set of vectors. The origin vector can be validated with the results; the controls can be included in the process of generating the results and induced behaviors can be monitored, according to the parameters required for the system, managing in this way an approximation of the environmental entity's behaviors that the user wishes to study.

Future work can be presented, as case studies in environmental problems related to the use of the soil, climate, flora and fauna. Also, in the same category of water resources but focused on other situations, the Multi-AVNG system can be used to monitor and highlight environmental problems.

\section{ACKNOWLEDGMENTS}

This article is based on the doctoral thesis "An approach to environmental management Piedemonte Colombian Amazonico (Florence, Caquetá) from computer bioinspired high performance" which was researched under the auspices of the Ph.D. program in engineering at the University Distrital "Francisco José de Caldas", Bogotá, Colombia and with the support of the University of Amazonia in Florencia, Caquetá, Colombia.

\section{REFERENCES}

BATTY, M. Geocomputation using cellular automata. Geocomputation. New York: Taylor \& Francis, 2000. p. 95-126. 
CHEN, S. H.; JAKEMAN, A. J.; NORTON, J. P. Artificial intelligence techniques: an introduction to their use for modelling environmental systems. Mathematics and Computers in Simulation, v. 78, n. 2, p. 379-400, 2008. http://dx.doi.org/10.1016/j. matcom.2008.01.028

CUESTA, F.; BECERRA, M. T. Biodiversity and climate change in the Andes: Importance of monitoring and regional work. Virtual magazine. REDESMA, v. 6, p. 19-32, 2012.

HAMMAM, Y.; MOORE, A.; WHIGHAM, P. The dynamic geometry of geographical vector agents. Computers, Environment and Urban Systems, v. 31, n. 5, p. 502-519, 2007. http://dx.doi.org/10.1016/j.compenvurbsys.2007.08.003

HORRITT, M. S.; BATES, P. D. Evaluation of 1D and 2D numerical models for predicting river flood inundation. Journal of Hydrology, v. 268, n. 1, p. 87-99, 2002. http://dx.doi.org/10.1016/S0022-1694(02)00121-X

INSTITUTO DE HIDROLOGÍA, METEOROLOGÍA Y ESTUDIOS AMBIENTALES IDEAM. Data IDEAM. Available in: http://www.ideam.gov.co. Access: 17 Jan. 2015.

JAYAWARDENA, A. W.; ZHU, B.; AMARASEKARA, J. D.; VEREIVALU, V. A. Comparative study of fuzzy logic systems approach for river discharge prediction. Journal of hydrology, v. 514, p. 85-101, 2014. http://dx.doi.org/10.1016/j. jhydrol.2014.03.064

SANTAMARÍA, B.; BALLESTEROS, J.; GONZÁLEZ, J. S. Cloud computing platform as technological infrastructure for virtual, remote and adaptive laboratories. Scientific Journal, v. 3, n. 23, p. 98-110, 2015.

VITABILE, S.; CONTI, V.; MILITELLO, C.; SORBELLO, F. An extended JADE-S based framework for developing secure Multi-Agent Systems. Computer Standards \& Interfaces, v. 31, n. 5, p. 913-930, 2009. http://dx.doi.org/10.1016/j.csi.2008.03.017 